\title{
IMPLEMENTASI KOMBINASI 3IC TOOLS SEBAGAI PENENTU OPTIMASI PENGENDALIAN PERSEDIAAN MINYAK GORENG
}

\author{
Hery Purnomo', Lilia Pasca Riani² \\ 1,2 Fakultas Ekonomi, Universitas Nusantara PGRI, Kediri
}

\begin{abstract}
Abstrak
Tujuan penelitian ini adalah untuk: (1) menentukan merek minyak goreng yang masuk klasifikasi kelas A menggunakan metode ABC, (2) menentukan besarnya safety stock yang harus disediakan, dan (3) menentukan reorder point paling banyak untuk produk minyak goreng yang masuk pada kelas A. Penelitian ini merupakan jenis penelitian deskriptif dengan pendekatan kuantitatif. Pengumpulan data dilakukan berdasarkan hasil observasi dan wawancara. Teknik analisis data dilakukan menggunakan 3 Inventory Control Tools (3IC Tools) yang terbagi dalam 3 tahapan yaitu; tahap pertama, analisis $A B C$ untuk mengklasifikasikan produk pada kelas A, B, atau C; tahap kedua, menghitung safety stock pada produk minyak goreng yang masuk kelas A; dan tahap ketiga, menentukan besarnya reorder oint. Hasil penelitian ini menunjukkan bawah dari 86 jenis merek dan kemasan minyak goreng, terdapat 28 merek yang masuk kategori kelas A, dengan perhitungan safety stock terbesar ada pada minyak goreng merek Sedaap kemasan refill 2 liter, dan reorder point paling banyak pada minyak goreng merek Rosebrand kemasan refill 1 liter.
\end{abstract}

Kata Kunci : $\quad$ Minyak goreng, 3IC tools, metode ABC, safety stock, reorder point.

\begin{abstract}
The purposes of this study are: (1) to classify the brand of the cooking oil product in the class A category using ABC method, (2) to identify the safety stock level of the inventory, and (3) to determine the highest reorder point for the cooking oil product in class A. This research is a descriptive research with quantitative approach. Data were collected based on observational studies and interviews. Data analysis was performed using 3IC tools divided into three stages: first, $A B C$ analysis to classify product class in class $A, B$, or $C$; second, calculating the safety stock level for the class A cooking oil; and third, determining the reorder point. The results showed that of the 86 cooking oil's brands and packagings, 28 brands were classified in class A; the highest safety stock calculation was on Sedaap brand cooking oil packaged in 2 liter refill, and the highest reorder point level was on the Rosebrand cooking oil packaged in 1 liter refill.
\end{abstract}

Keywords : Cooking oil, 3IC tools, ABC method, safety stock, reorder point. 


\section{Pendahuluan}

Retail modern seperti Toserba, Swalayan, dan Supermarket dewasa ini mulai berkembang pesat seiring dengan perkembangan teknologi tepat guna berbiaya murah yang beredar di masyarakat, antara lain teknologi komputerisasi pencatatan produk-produk di gudang hingga teknologi aplikasi multimedia berbasis jaringan sosial. Hal tersebut memunculkan persaingan yang semakin ketat antar retailer modern, antara lain dari segi penentuan harga, kualitas produk yang dijual, hingga pelayanannya, dan variasi produk. Retailer dituntut untuk menyediakan sebanyak banyaknya variasi untuk satu macam produk saja, sehingga konsumen dapat memilih dengan leluasa dengan memperbandingkan harga dan kualitas produk dengan merek lain namun tetap dalam satu retailer. Dengan kata lain, persediaan barang dagang untuk retailer sangat penting, Menurut Ishak (2010) persediaan adalah sumber daya menganggur (Idle Resource) yang belum digunakan karena menunggu proses yang lebih lanjut, proses lebih lanjut disini berupa kegiatan produksi. Sejalan dengan itu menurut Martani et al., (2012) persediaan merupakan salah satu aset yang penting bagi entitatas baik bagi perusahaan ritel, manufaktur, jasa, maupun entitas lainnya.

Semakin banyak variasi untuk satu jenis produk, menyebabkan semakin banyak alokasi investasi untuk menjaga jangan sampai satu produk mengalami stock out, terutama untuk jenis produk konsumsi sehari-hari, antara lain produk perlengkapan mandi, produk kecantikan, dan bahan-bahan makanan. Pengelola retailer harus jeli dalam menentukan jenis produk mana yang harus diadakan persediaan yang banyak maupun sedikit, jenis produk yang paling banyak atau sering dibeli oleh konsumen, jenis produk yang memiliki kontribusi paling tinggi dalam proyeksi laba, maupun produk yang margin labanya rendah. Begitu juga dengan kombinasinya, semisal jenis produk yang paling banyak atau sering dibeli oleh konsumen namun margin labanya rendah, atau produk yang jarang dibeli namun margin labanya besar untuk perusahaan.
Peretail harus mampu mengelola barang dagangannya dengan meningkatkan kegiatan pengendalian persediaan barang dagangan, agar target laba perusahaan tercapai sekaligun dapat menyeimbangkan antara persediaan barang yang ada digudang dengan permintaan konsumen. Secara teori terdapat banyak metode yang dapat diimplementasikan terkait pengendalian persediaan (Inventory Control) barang dagangan, yakni analisis $\mathrm{ABC}$, dan perhitungan safety stock yang dilengkapi dengan penentuan Reorder Point yang sering dikenal dengan istilah atau Three Inventory Control Tools (3IC Tools) atau 3 alat pengendalian persediaan.

Metode tersebut dinilai efektif dalam pengendalian persediaan karena terkait dengan efisiensi biaya persediaan. Perusahaan dapat menekan biaya seminimal mungkin dengan perhitungan matematis dan statistik berapa barang yang harus dipesan dan disediakan agar biayanya paling rendah. Menurut Heizer \& Render (2014) analisis ABC membagi persediaan yang dimiliki kedalam tiga golongan berdasarkan pada volume dollar tahunan. Analisis ABC adalah sebuah aplikasi persediaan dari prinsip Pareto. Prinsip Pareto menyatakan bahwa terdapat "sedikit hal yang penting dan banyak hal yang sepele." Tujuannya adalah membuat kebijakan persediaan yang memusatkan sumber daya pada komponen persediaan penting yang sedikit dan bukan pada yang banyak namun sepele.

Lebih lanjut Heizer \& Render (2014) untuk menentukan volume dollar tahunan analisis ABC dalam hal ini adalah volume Rupiah, permintaan tahunan dari setiap barang persediaan dihitung dan dikalikan dengan harga per unit. Barang Kelas A adalah barangbarang dengan volume rupiah tahunan tinggi. Walaupun barang seperti ini mungkin hanya mewakili sekitar $15 \%$ dari total persediaan barang, mereka merepresentasikan 70\% hingga $80 \%$ dari total pemakaian dollar. Kelas $B$ adalah untuk barang-barang persediaan yang memiliki volume dollar tahunan menengah. Barang ini merepresentasikan 30\% barang persediaan dan 15\% hingga 25\% dari nilai total. Barang-barang yang memiliki volume dollar tahunan rendah adalah Kelas $C$, yang mungkin hanya merepresentasikan 5\% 
dari volume dollar tahunan tetapi sekitar 55\% dari total barang persediaan.

Assauri (1999) menyebutkan kriteria selain dari volume dollar tahunan juga dapat menentukan penggolongan barang. Sebagai contoh, perubahan yang diantisipsi, permasalahan pengiriman, permasalahan kualitas, atau biaya per unit yang tinggi dapat menaikkan barang ke penggolongan yang lebih tinggi. Keuntungan dari pembagian barang persediaan ke dalam tiga kelas ini memungkinkan diterapkannya kebijakan dan kontrol untuk setiap kelas. Menurut Hadi (2004) Kebijakan yang mungkin didasarkan padaanalisis $\mathrm{ABC}$ meliputi hal berikut :

1. Pembelian sumber daya yang dibelanjakan pada pengembangan pemasok harus jauh lebih tinggi untuk barang A dibanding barang $\mathrm{C}$.

2. Barang A tidak seperti barang B dan C, perlu memiliki kontrol persediaan fisik yang lebih ketat; mungkin mereka dapat diletakkan pada tempat yang lebih aman, dan mungkin akurasi catatan persediaan untuk barang A harus lebih sering diverifikasi.

3. Prediksi barang-barang A perlu dijamin keabsahannya dibandingkan dengan prediksi barang B dan C.

Prediksi yang lebih baik, kontrol fisik, keandalan pemasok, dan pengurangan persediaan pengaman, semuanya merupakan hasil dari kebijakan manajemen persediaan yang sesuai. Analisis ABC mengarahnkan pengembangan semua kebijakan tersebut.

Menurut Rangkuti (2007) metode analisis ABC pada umumnya digunakan untuk jumlah persediaan yang banyak jumlahnya yang masing-masing barang membutuhkan analisis untuk mengetahui besarnya jumlah pemesanan. Namun demikian menurut Herjanto (2008) perlu disadari bahwa berbagai jenis barang yang ada dalam persediaan tersebut tidak seluruhnya memiliki tingkat prioritas yang sama. sehingga untuk mengetahui jenis-jenis barang yang perlu mendapat prioritas dapat dianalisis dengan metode ABC. Analisis ini dapat mengkasifikasikan seluruh jenis barang berdasarkan tingkat kepentingannya.
Menurut Heizer \& Render (2014) persediaan pengaman (safety stock) adalah persediaan tambahan sebagai suatu penyangga yang memungkinkan terjadinya ketidaksamaan permintaan. Adanya Safety stock bahkan security stock sebagai sumber inefisiensi (waste). Oleh karena itu sebisa mungkin persediaan minimal jumlahnya harus ditekan.

Persediaan pengaman (safety stock) berguna untuk melindungi perusahaan dari risiko kehabisan bahan baku (stock out), keterlambatan penerimaan bahan baku yang dipesan, dan dapat juga bermanfaat ketika terjadi lonjakan permintaan yang tidak terprediksi sebelumnya oleh perusahaan (Hadi, 2004). Dalam analisis penyimpangan ini manajemen perusahaan menentukan seberapa jauh bahan baku yang masih dapat diterima.

Menurut Rangkuti (2007), persediaan pengaman adalah persediaan tambahan yang diadakan untuk melindungi atau menjaga kemungkinan terjadinya kekurangan bahan. Ada beberapa faktor yang menentukan besarnya persediaan pengaman, yaitu:

1. Rataan tingkat permintaan dan rataan masa tenggang

2. Keragaman permintaan pada masa tenggang

3. Keinginan tingkat pelayanan yang diberikan.

Perhitungan persediaan pengaman adalah sebagai berikut:

$S D=\sqrt{\frac{\sum(x-\bar{x})^{2}}{n}} \quad S S=S D \times Z$

Dimana :

$\mathrm{SD}=$ Standar deviasi

$\bar{X}=$ Rata-rata kebutuhan

$\mathrm{X}=$ Data Kebutuhan

$\mathrm{n} \quad=$ Jumlah data

$\mathrm{Z}=$ nilai tabel standar deviasi untuk penyimpangan $5 \%=1,65$

Sebagai pelengkap dalam memenuhi target efektifitas dan efisiensi barang dagangan, maka metode tambahan yang dapat diterapkan adalah penentuan Reorder Point. Menurut Sugiono (2009) Reorder Point merupakan titik atau posisi (status) persediaan dimana perusahaan harus 
melakukan pemesanan ulang sedemikian rupa agar tidak terjadi kehabisan persediaan sehingga pada saat persediaan berada pada titik nol atau pada level safety stock, terjadi penerimaan material yang dipesan. Terutama untuk produk yang dinilai memiliki volume penjualan yang tinggi dan margin laba yang relative besar (Dewi, 2010). Terdapat beberapa hal yang harus diperhatikan dalam menentukan besarnya Reorder Point, yaitu :

1. Penggunaan / kebutuhan barang selama masa tenggang (lead time)

2. Besarnya buffer stock / safety stock

Sehingga penentuan Reorder Ponit tampak pada rumus sebagai berikut :

$R O P=($ Lead Time $\mathrm{x}$ Kebutuhan Perhari $)+$ Safety Stock

Salah satu perusahaan retail yang sedang berkembang adalah swalayan Mina yang berlokasi di Jalan Raya Kediri-Nganjuk, Kecamatan Grogol, Kabupaten Kediri. Berdasarkan observasi awal, terdapat beberapa permasalahan yang dihadapi Swalayan Mina terkait pengendalian persediaan barang dagangannya, yakni pada produk minyak goreng. Produk ini menjadi salah satu jenis produk yang banyak atau sering dibeli, dengan margin laba yang besar jika dibandingkan dengan produk konsumsi yang lain. Produk minyak goreng sendiri memiliki banyak varian merek dan kemasan. Permasalahan lain adalah produk minyak goreng ini memiliki lead time pemesanan yang relatif lebih lama menyebabkan sering terjadi stock out untuk merek tertentu. Swalayan Mina belum menerapkan sistem pengendalian barang dagangan yang efektif guna menjaga stabilitas keluar masuk barang dagangannya. Berdasarkan latar belakang permasalahan diatas, maka penulis membahas Implementasi Kombinasi Metode ABC, Safety Stock, Dan Reorder Point Sebagai Penentu Optimasi Pengendalian Persediaan Minyak Goreng pada Swalayan Mina, Kecamatan Grogol, Kabupaten Kediri"

\section{Metodologi}

Penelitian ini termasuk jenis penelitian deskriptif. Tujuan dari penelitian deskriptif adalah untuk membuat deskripsi, gambaran, atau lukisan secara sistematis, faktual, dan akurat mengenai fakta-fakta, sifat-sifat serta hubungan antar fenomena yang diselidiki. Sedangkan Penelitian ini menggunakan pendekatan kuantitatif.

Subyek penelitian ini adalah Swalayan Mina yang beralamat di Jalan Raya Kediri Nganjuk, Desa Wonoasri, Kecamatan Grogol, Kabupaten Kediri. Objek dari penelitian ini adalah persediaan barang dagang berupa Minyak Goreng.

Terdapat 3 tahapan dalam teknik analisa data menggunakan 3IC Tools, yang pertama adalah menentukan kelas dalam analisis $\mathrm{ABC}$, dan yang kedua adalah menghitung safety stock untuk produk minyak goreng yang masuk dalam kelas A.

1. Tahap analisis $A B C$, dalam tahap ini terdiri dari 4 langkah perhitungan, yaitu
a. Menghitung volume tahunan penjualan minyak goreng dengan menggandakan data harga dan penjualan minyak goreng tahun 2016
b. Mengurutkan identitas minyak goreng dari volume yang paling besar
c. Menghitung nilai kumulatif dan prosentase kumulatif
d. Menentukan kelas

2. Tahap menghitung safety stock, perhitungan safety stock dilakukan pada produk minyak goreng yang masuk kelas A pada tahap sebelumnya. Dalam perhitungan ini terdapat 4 langkah, yaitu :
a. Menghitung standar deviasi data persediaan produk minyak goreng
b. Menghitung safety stock

3. Tahap menentukan letak Reoder Point, dilakukan pada produk minyak goreng yang masuk kelas A pada perhitungan tahap 1 dan memiliki lead time optimum. Dalam menentukan besarnya ROP terdapat 3 langkah, yaitu :
a. Menginventarisasi data lead time minyak goreng selama 30 hari yakni dibulan Oktober 2017 untuk menentukan lead time optimum
b. Menentukan tingkat kebutuhan barang dagangan perhari
c. Mengalikan lead time optimum dengan kebutuhan barang dagangan perhari

d. Menentukan ROP dengan cara menambahkan hasil kali pada langkah 
c dengan besaran safety stock yang telah ditentukan pada tahap ke 2 .

\section{Hasil dan Pembahasan}

1. Analisis ABC

Pada tahap ini terdapat 4 langkah untuk mengetahui prioritas minyak goreng, yaitu:

a. Mengidentifikasi merek dan kemasan minyak goreng

Tabel 1. Identifikasi Merek Dan Kemasan Minyak Goreng

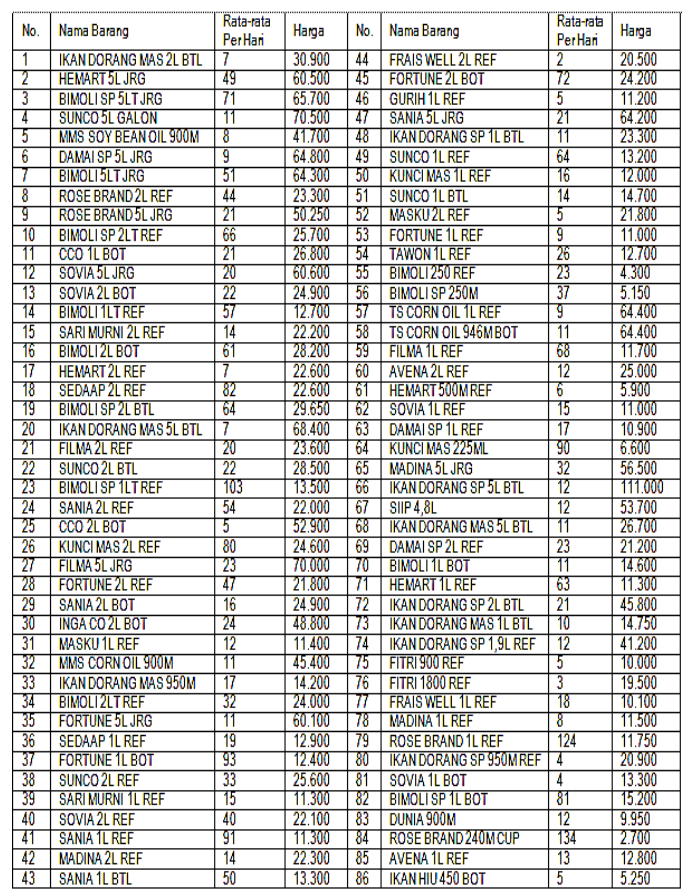

Sumber: Hasil Analisis Data

Berdasarkan data di atas, dapat diidentifikasi sebanyak 86 kemasan minyak goreng dari berbagai merk. Adapun permintaan perhari paling banyak adalah pada minyak goreng merek Rose Brand pada kemasan 240m Cup. Sedangkan harga paling mahal adalah Merek Ikan Dorang SP 5L Kemasan Botol.

b. Mengurutkan identitas minyak goreng dari volume permintaan tahunan yang paling besar
Tabel 2. Urutan Identitas Minyak Goreng Berdasarkan Volume Tahunan

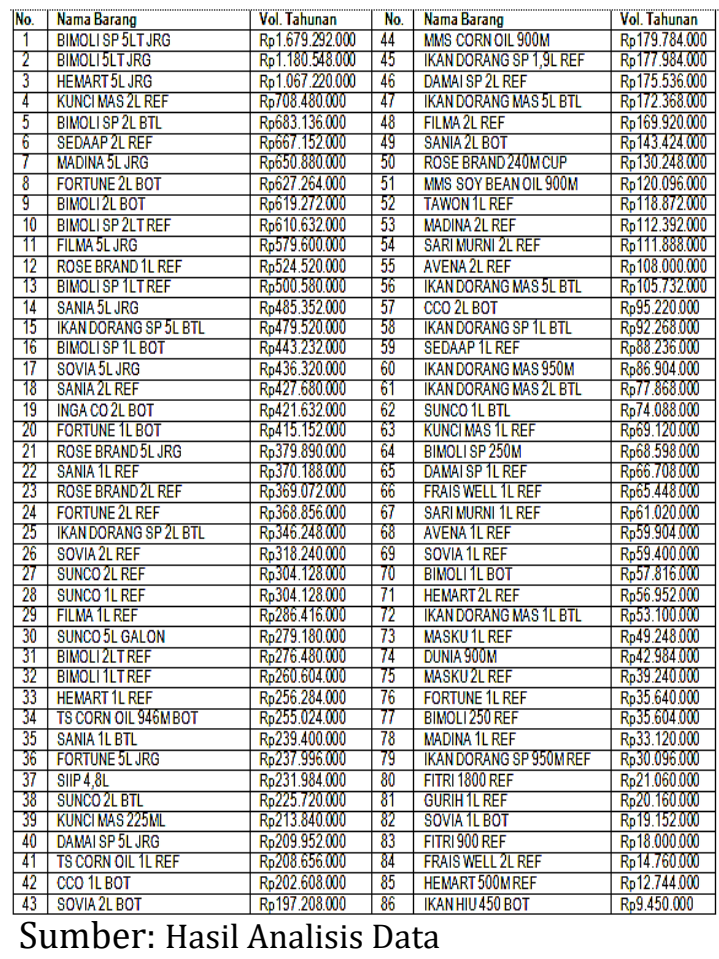

Tabel 2 diatas menunjukkan urutan volume tahunan minyak goreng, volume tahunan merupakan hasil kali dari permintaan perbulan dengan harga perunit nya. Nilai volume tahunan paling besar diperoleh minyak goreng merek Bimoli SP 5LT Jrg, sedangkan nilai volume tahunan terendah ditunjukkan pada merek Ikan Hiu 450 Botol

c. Menghitung nilai kumulatif dan prosentase kumulatif

Nilai Kumulatif diperoleh berdasarkan tabel sebelumnya, yakni pada volume tahunan ditambahkan volume tahunan urutan berikutnya, sehingga menghasilkan volume tahunan total sebesar Rp. 22.889.718.000,00. Nilai volume tahunan total digunakan untuk menghitung prosentae kumulatif. 
Tabel 3. Nilai Kumulatif dan Prosentase Kumulatif

\begin{tabular}{|c|c|c|c|c|c|c|c|}
\hline \$1 & Nama Barang & Kumulatif & $\begin{array}{c}9 \\
\text { Kum } \\
\end{array}$ & No, & Nama Barang & Kumulatif & $\begin{array}{c}9 \\
\text { Kum }\end{array}$ \\
\hline 1 & BDNOLISP 5LTRRG & 92000 & 7,34 & 44 & MMSCC & 600000 & 86,19 \\
\hline 2 & BDMOLI5 & & 12,49 & 45 & $\mathbb{I K A N D C}$ & & 86,97 \\
\hline$\beta$ & HEMART 5LJRG & 1927.060 .000 & 17,16 & 46 & DAMAISP 2LREF & $20,082,870.000$ & 87,74 \\
\hline 4 & KUNCIMA & 000 & 20,25 & 47 & IKAN DORAI & 20.255 .238 .000 & 88,49 \\
\hline 5 & BDMOLISP & 000 & 23,24 & 48 & FLLMA2LREF & 88,000 & 89,23 \\
\hline 6 & SEDAAP 2LREF & 5.985 .828000 & 26,15 & 49 & SANIA 2L BOT & Rp20.568.5822000 & 89,86: \\
\hline 7 & MADNAS & 000 & 28,99 & 50 & ROSE BR & 30,000 & 90,43 \\
\hline 8 & FORTUNE & 00 & 31,73 & 51 & MMSSOY & 60000 & 90,95 \\
\hline 5 & BDMOLI2L BOT & 000 & 34,44 & 52 & TAWON 1LREF & 798000 & 91,47 \\
\hline 10 & BMYOLISP 2LTR & 100 & 37,11 & 53 & MADNA2 & Rp21.050,190,000 & 91,96: \\
\hline 11 & FILMASL] & 100 & 39,64 & 54 & SARMUR & 78000 & 92,45 \\
\hline 12 & ROSE BRAND 1LREF & 9.597 .9 & 41,93 & 55 & \begin{tabular}{|l|} 
AVENA 2LREP \\
\end{tabular} & Rp21.270.078.000 & 92,92 \\
\hline 13 & BMOLLSP & .000 & 44,12 & 56 & [KRAN DORANG]. & Rp21.375.810.000 & 93,39 \\
\hline 14 & SANA 5 L & 00 & 46,24 & 57 & $\mathrm{CCO} 2 \mathrm{LBC}$ & 0000 & 93,80 \\
\hline 15 & IRAN DORAMG SP is BTL & 000 & 48,33 & 58 & IKANDOR & 88000 & 94,21 \\
\hline 16 & BMOLISP IL BOT & 100 & 50,27 & 59 & SEDAAP1 & 534.000 & 94,59 \\
\hline 17 & SOVIA 5L) & $11.945,0000000$ & 52,18 & 60 & IKAN DOR. & 88000 & 94,97 \\
\hline 18 & SANIA 2L REP & $12,370,680.000$ & 54,04 & 61 & [KAN DORA & Rp21.816,306,000 & 95,31 . \\
\hline 19 & INGACO2 & 00 & 55,89 & 62 & SUNCO 1t & Rp21.8 & 95,63 \\
\hline 20 & FORTUNE & & 57,70 & 63 & KuNCIM & 4000 & 95,94 \\
\hline 21 & ROSE BRA & 100 & 59,36 & 64 & BRMOLIS: & Rp22. & 96,24 \\
\hline 22 & SANLA 1LREF & 100 & 60,98 & 65 & DAMAISF & $\operatorname{Rp} 22.0$ & 96,53 \\
\hline 23 & ROSE BRAND 2LRE & $14,326,6144,000$ & 62,59 & 66 & FRAISWE & Rp22.160.2688.000 & 96,81 \\
\hline 24 & FORTUNE 2LREF & $14,695,470,000$ & 64,20 & 67 & SARIMURN & $\operatorname{Rp} 22,221,288,000$ & 97,08 \\
\hline 25 & IRAN DDRAMC SP ZL B & Rp15.041 & 65,71 & 68 & AVENA1 & 192000 & 97,34 \\
\hline 26 & SOVIA 2L & & 67,10 & 69 & SOTZAIL & 2000 & 97,60 \\
\hline 27 & \begin{tabular}{|l} 
SUNCO ZLREP \\
\end{tabular} & 00 & 68,43 & 70 & BMOLLIL & Rp22,3 & 97,85 \\
\hline 28 & SUNCO ILREF & 15.968 & 69,76 & 71 & HEMART ZLREF & Rp222.455,3600000 & 98,10 \\
\hline 29 & FLLMA ALREF & 00 & 71,01 & 72 & $\begin{array}{l}\text { IKAN DORANGM } \\
\end{array}$ & $\operatorname{Rp} 22.508 .460 .000$ & 98,33 \\
\hline 30 & SUNCO SLGALON & 000 & 72,23 & 73 & \begin{tabular}{|l|} 
MASSWU 1L REF \\
\end{tabular} & Rp22,557,708:000 & 98,55 \\
\hline 31 & BDMOLL2LTREF & Rp16.810,290,000 & 73,44 & 74 & DUNA 900M & Rp22,600,692000 & 98,74 \\
\hline 32 & BMOLI & & 74,58 & 75 & MASKO 2 & Rp22.6 & 98,91 \\
\hline 33 & HEMART IL REF & 00 & 75,70 & 76 & FORTUNE & Rp22,6 & 99,06 \\
\hline 34 & TS CORN OLI96M BOT & Rpp17.582.202.000 & 76,81 & 77 & BMMOLI250 REF & Rp22.711.176,000 & 99,22 \\
\hline 35 & SANIA ALBTL & 00 & 77,86 & 78 & MADNA 1 & Rp22.7. & 99,36 \\
\hline 36 & FORTUNE ELJR & 000 & 78,90 & 79 & IIKAN DORANGSP & Rp22,774,3920000 & 99,50 \\
\hline 37 & SIIP 4,8L & 18.291 .582000 & 79,91 & 80 & FITR 1800 REF & Rp22.795.452000 & 99,59: \\
\hline 38 & SUNCO 2L BTL & 100 & 80,90 & 81 & GURHH 1LREF & Rp22.81 & 99,68 : \\
\hline 39 & KUNCIMAS 225ML & Rp18.731 & 81,83 & 82 & SOVIA ALBOT & $\operatorname{Rp} 22.834 .764 .000$ & 99,76 \\
\hline 40 & DAMAISP 5L/RG & Rp18.941.094:000 & 82,75 & 83 & FTRR1900 REF & Rp22.852.764:000 & 99,84 \\
\hline 41 & TSCORNOI & 00 & 83,66 & 84 & FRAISWELL 2LREF & Rp22.86 & 99,90 \\
\hline 42 & CCO 1LBOT & 3000 & 84,55 & 85 & HEMART 5OOMREF & Rp22.880.268.000 & 99,96: \\
\hline 43 & SOTZA 2L BOT & Rp19.549.566.000 & 85,41 & 86 & IKAN HIOU 450 BOT & Rp22,889,718.000 & 100,00 \\
\hline
\end{tabular}

Sumber: Hasil Analisis Data

\section{d. Menentukan kelas}

Tabel 4 di bawah menunjukkan bahwa terdapat 28 item minyak goreng yang masuk pada kelas A, 21 item masuk pada kelas B, sedangkan sisanya sebanyak 31 item masuk pada kelas C. Penentuan kelas ini dapat digunakan sebagai acuan dalam pengambilan keputusan mengenai item minyak goreng apa saja yang harus di utamakan persediaanya, karena terkait dengan antisipasi out of stock.
Tabel 4. Penentuan Kelas

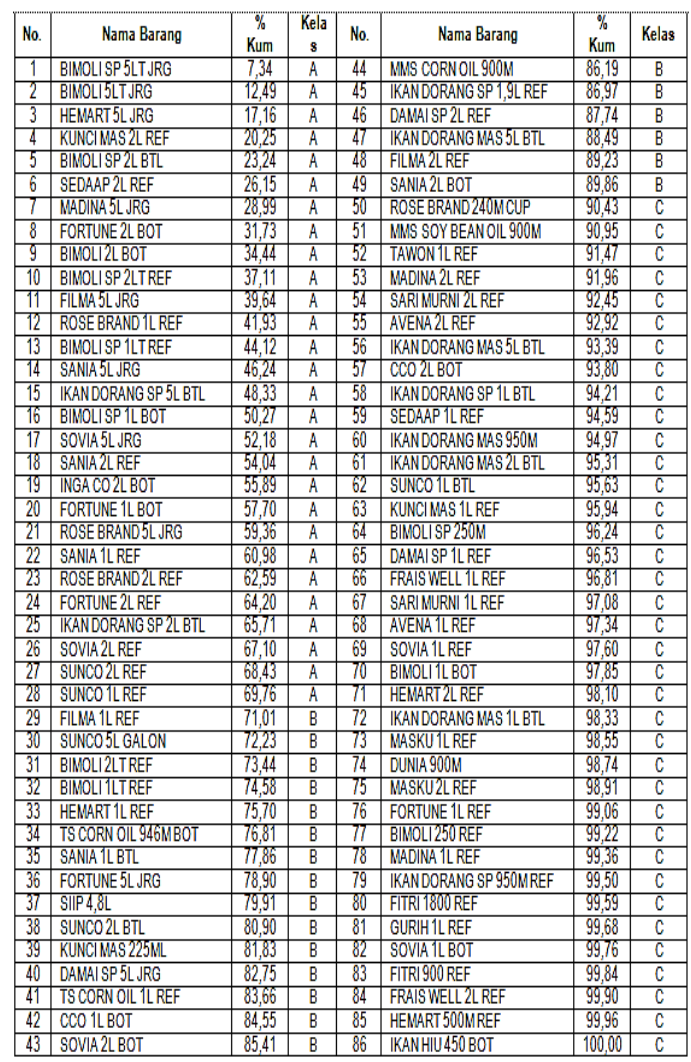

Sumber: Hasil Analisis Data

\section{Perhitungan Safety Stock}

Masuk pada tahap perhitungan Safety Stock, terdapat 3 langkah, yaitu :

a. Menghitung standar deviasi data persediaan produk minyak goreng

\section{Tabel 5. Perhitungan Standar Deviasi}

\begin{tabular}{|l|l|l|l|l|l|}
\hline No. & Nama Barang & STDEV & No. & Nama Barang & STDEV \\
\hline 1 & BIMOLI SP 5LT JRG & 17,88 & 15 & IKAN DORANG SP 5L BTL & 12,96 \\
\hline 2 & BIM0LI 5LT JRG & 12,92 & 16 & BIM0LI SP 1L B0T & 14,40 \\
\hline 3 & HEMART 5LJRG & 29,28 & 17 & SOVIA 5L JRG & 17,62 \\
\hline 4 & KUNCI MAS 2L REF & 21,90 & 18 & SANIA 2L REF & 14,57 \\
\hline 5 & BIM0LI SP 2L BTL & 28,52 & 19 & INGA C0 2L B0T & 12,43 \\
\hline 6 & SEDAAP 2L REF & 251,77 & 20 & F0RTUNE 1L B0T & 41,51 \\
\hline 7 & MADINA 5LJRG & 31,64 & 21 & R0SE BRAND 5LJRG & 8,06 \\
\hline 8 & FORTUNE 2L B0T & 28,07 & 22 & SANIA 1L REF & 46,30 \\
\hline 9 & BIM0LI 2L B0T & 23,23 & 23 & ROSE BRAND 2L REF & 71,23 \\
\hline 10 & BIMOLI SP 2LT REF & 28,88 & 24 & F0RTUNE 2L REF & 24,03 \\
\hline 11 & FILMA 5LJRG & 22,48 & 25 & IKAN D0RANG SP 2L BTL & 18,54 \\
\hline 12 & ROSE BRAND 1L REF & 115,38 & 26 & SOVIA 2L REF & 26,35 \\
\hline 13 & BIMOLI SP 1LT REF & 162,01 & 27 & SUNC0 2L REF & 28,42 \\
\hline 14 & SANIA 5L JRG & 27,81 & 28 & SUNC0 1L REF & 27,58 \\
\hline
\end{tabular}

Sumber: Hasil Analisis Data

Standar deviasi dalam hal ini merupakan angka penyimpangan standar berdasarkan data permintaan perbulan, adapun penyimpangan terbesar dihasilkan oleh item merek Sedaap 2L Ref, sedangkan penyimpangan terkecil ditunjukkan oleh item Rose Brand 5L Jrg, 
yakni 8. Hasil perhitungan standar deviasi ini digunakan untuk menentukan level safety stock.

b. Menghitung safety stock

Persediaan yang harus ada digudang adalah paling banyak dari item Sedaap 2L Ref yaitu 252 buah. Sedangkan safety stock paling sedikit pada item Bimoli 5L, Ikan Dorang SP 5L BTL, dan Inga Co 2L BOT masing-masing sebanyak 21 buah.

\section{Tabel 6. Penentuan Besarnya} Safety Stock

\begin{tabular}{|c|c|c|c|c|c|c|c|}
\hline No. & Nama Barang & STDEV & SS & $\mathrm{No}$. & Nama Barang & STDEV & SS \\
\hline 1 & BIM0LISP 5LTJRG & 17,88 & 30 & 15 & IKAN DORANG SP 5L BTL & 12,96 & 21 \\
\hline 2 & BIM0LI5LTJRG & 12,92 & 21 & 16 & BIMOLI SP 1L BOT & 14,40 & 24 \\
\hline 3 & HEMART 5LJRG & 29,28 & 48 & 17 & SOVIA 5LJRG & 17,62 & 29 \\
\hline 4 & KUNCIMAS 2L REF & 21,90 & 36 & 18 & SANIA 2L REF & 14,57 & 24 \\
\hline 5 & BIMOLI SP 2L BTL & 28,52 & 47 & 19 & INGA CO 2L BOT & 12,43 & 21 \\
\hline 6 & SEDAAP 2LREF & 251,77 & 415 & 20 & FORTUNE 1L BOT & 41,51 & 68 \\
\hline 7 & MADINA 5LJRG & 31,64 & 52 & 21 & ROSE BRAND 5LJRG & 8,06 & 13 \\
\hline 8 & FORTUNE 2L BOT & 28,07 & 46 & 22 & SANIA 1L REF & 46,30 & 76 \\
\hline 9 & BIMOLI 2L BOT & 23,23 & 38 & 23 & ROSE BRAND 2L REF & 71,23 & 118 \\
\hline 10 & BIMOLISP ZLTREF & 28,88 & 48 & 24 & FORTUNE 2L REF & 24,03 & 40 \\
\hline 11 & FLLMA 5LJRG & 22,48 & 37 & 25 & IKAN DORANG SP 2L BTL & 18,54 & 31 \\
\hline 12 & ROSE BRAND 1L REF & 115,38 & 190 & 26 & SOVIA 2L REF & 26,35 & 43 \\
\hline 13 & BIMOLI SP 1LTREF & 162,01 & 267 & 27 & SUNCO LLREF & 28,42 & 47 \\
\hline 14 & SANIA 5LIRG & 27,81 & 46 & 28 & SUNCO 1LREF & 27,58 & 45 \\
\hline
\end{tabular}

Sumber: Hasil Analisis Data

\section{Menentukan Reorder Point}

a. Menginventarisasi data lead time minyak goreng selama 30 hari yakni di bulan Oktober 2017 untuk menentukan lead time optimum

Data lead time perusahaan untuk produk minyak goreng diketahui bervariasi antara 4, 5, 6, dan 7 hari pengiriman sampai barang datang di gudang Swalayan Mina, sehingga dalam penelitian ini akan dihitung reorder point untuk lead time dengan frekuensi terbanyak yang menunjukkan lead time tersebut paling sering terjadi.

Berikut adalah data lead time selama 30 kali pemesanan :
Tabel 7. Data Lead Time Selama 30 Kali Pemesanan

\begin{tabular}{|c|c|}
\hline $\begin{array}{c}\text { Lead Time } \\
\text { (hari) }\end{array}$ & Frekuensi \\
\hline & \\
4 & 3 \\
5 & 8 \\
6 & 5 \\
7 & 14 \\
\hline Jumlah & 30 \\
Pemesanan & \\
\hline
\end{tabular}

Sumber: Hasil Analisis Data

Dari tabel 7 tampak bahwa lead time yang paling sering terjadi adalah 7 hari dengan frekuensi 14 kali pemesanan. Sehingga lead time ini digunakan dalam perhitungan menentukan besarnya Reorder Point.

Data diatas merupakan data hasil perhari selama 1 tahun dengan 364 hari kerja. Data perhitungan kebutuhan barang dagangan untuk produk minyak goreng per hari digunakan untuk menentukan besarya kebutuhan minyak goreng selama masa lead time.

b. Menentukan tingkat kebutuhan barang dagangan perhari

Tabel 8. Data Kebutuhan Minyak Goreng Per Hari

\begin{tabular}{|c|c|c|c|c|c|c|c|}
\hline No. & Nama Barang & $\begin{array}{l}\text { Kebutuhlan } \\
\text { pertahun }\end{array}$ & $\begin{array}{l}\text { Kebutuhan } \\
\text { Perlhari }\end{array}$ & No. & Nama Barang & $\begin{array}{l}\text { Kebutuhan } \\
\text { Pertahun }\end{array}$ & $\begin{array}{l}\text { Kebutuhan } \\
\text { Perhari }\end{array}$ \\
\hline 1 & BIMOLISP 5LTJRG & 25560 & 71 & 15 & $\begin{array}{l}\text { IKAN DORANG SP } \\
\text { 5L.BTL } \\
\end{array}$ & 4320 & 12 \\
\hline 2 & BIMOLISLTRRG & 18360 & 51 & 16 & BIMOLI SP AL BOT & 29160 & 81 \\
\hline 3 & HEMART 5LJRG & 17640 & 49 & 17 & SOVIA 5L/RG & 7200 & 20 \\
\hline 4 & KUNCI MAS 2L REF & 28800 & 80 & 18 & SANIA 2L REF & 19440 & 54 \\
\hline 5 & BIMOLI SP 2L BTL & 23040 & 64 & 19 & INGA CO ZL BOT & 8640 & 24 \\
\hline 6 & SEDAAP 2L REF & 29520 & 82 & 20 & FORTUNE 1L BOT & 33480 & 93 \\
\hline 7 & MADINA 5L.JRG & 11520 & 32 & 21 & ROSE BRAND 5L.JRG & 7560 & 21 \\
\hline 8 & FORTUNE 2LBOT & 25920 & 72 & 22 & SANIA 1LREF & 32760 & 91 \\
\hline 9 & BIMOLI 2L BOT & 21960 & 61 & 23 & $\begin{array}{l}\text { ROSE BRAND } 2 \mathrm{~L} \\
\text { REF }\end{array}$ & 15840 & 44 \\
\hline 10 & BIMOLI SP 2LT REF & 23760 & 66 & 24 & FORTUNE 2LREF & 16920 & 47 \\
\hline 11 & FLLMA 5LIRG & 8280 & 23 & 25 & $\begin{array}{l}\text { IKAN DORANG SP } \\
\text { 2L.BTL. } \\
\end{array}$ & 7560 & 21 \\
\hline 12 & ROSE BRAND 1L REF & 44640 & 124 & 26 & SOVIA ZLREF & 14400 & 40 \\
\hline 13 & BIMOLL SP 1LT REF & 37080 & 103 & 27 & \begin{tabular}{|l|l|} 
SUNCO ZLREF \\
\end{tabular} & 11880 & 33 \\
\hline 14 & SANIA 5L IRG & 7560 & 21 & 28 & SUNCO ILREF & 23040 & 64 \\
\hline
\end{tabular}

Sumber: Hasil Analisis Data

Langkah kedua dalam tahap menentukan reorder point adalah menghitung tingkat kebutuhan perhari, dengan ketentuan perusahaan bahwa hari kerja ditentukan selama 364 hari dalam setahun. Table berikut merupakan data kebutuhan 
produk minyak goreng pertahun untuk minyak goreng yang masuk dalam kelas $\mathrm{A}$ dalam analisis ABC.

c. Mengalikan lead time optimum dengan kebutuhan barang dagangan perhari Lead time optimum yang dimaksud adalah lead time dengan frekuensi terbesar atau lead time yang paling sering terjadi dalam 30 kali pemesanan yaitu lead time 7 hari.

Tabel 9 merupakan hasil perhitungan kebutuhan barang dagangan minyak goreng selama lead time, yakni selama masa menunggu antara waktu pemesanan sampai barang dikirim dan sampai di gudang Swalayan Mina. Perhitungan kebutuhan selama lead time 7 hari merupakan salah satu komponen penentuan ROP selain besarnya safety stock.

Tabel 9. Data Kebutuhan Minyak Goreng Selama Lead Time 7 Hari

\begin{tabular}{|c|c|c|c|c|c|c|c|}
\hline No. & Nama Barang & $\begin{array}{l}\text { Kebutuhan } \\
\text { Perhari }\end{array}$ & \begin{tabular}{|l} 
Kebutuhan \\
selama \\
lead time
\end{tabular} & No. & Nama Barang & $\begin{array}{l}\text { Kebutuhan } \\
\text { Perhari }\end{array}$ & \begin{tabular}{|l|} 
Kebutuhar \\
selama \\
lead time
\end{tabular} \\
\hline 1 & BIMOLI SP 5LTJRG & 71 & 497 & 15 & $\begin{array}{l}\text { IKAN DORANG SP 5L } \\
\text { BTL } \\
\end{array}$ & 12 & 84 \\
\hline 2 & BIMOLL 5LT JRG & 51 & 357 & 16 & \begin{tabular}{|l|} 
BIMOLI SP 1L BOT \\
\end{tabular} & 81 & 567 \\
\hline 3 & HEMART 5L JRG & 49 & 343 & 17 & SOVIA 5L JRG & 20 & 140 \\
\hline 4 & KUNCI MAS 2L REF & 80 & 560 & 18 & SANIA 2L REF & 54 & 378 \\
\hline 5 & BIMOLI SP 2L BTL & 64 & 448 & 19 & INGA CO 2L BOT & 24 & 168 \\
\hline 6 & SEDAAP 2L REF & 82 & 574 & 20 & FORTUNE 1L BOT & 93 & 651 \\
\hline 7 & MADINA 5L JRG & 32 & 224 & 21 & ROSE BRAND 5LJRG & 21 & 147 \\
\hline 8 & FORTUNE 2L BOT & 72 & 504 & 22 & SANIA 1L REF & 91 & 637 \\
\hline 9 & BIMOLI 2L BOT & 61 & 427 & 23 & ROSE BRAND 2L REF & 44 & 308 \\
\hline 10 & BIMOLI SP 2LTREF & 66 & 462 & 24 & FORTUNE 2L REF & 47 & 329 \\
\hline 11 & FILMA 5L JRG & 23 & 161 & 25 & $\begin{array}{l}\text { IKAN DORANG SP 2L } \\
\text { BTL }\end{array}$ & 21 & 147 \\
\hline 12 & ROSE BRAND 1L REF & 124 & 868 & 26 & SOVIA 2L REF & 40 & 280 \\
\hline 13 & BIMOLISP ILT REF & 103 & 721 & 27 & $\begin{array}{l}\text { SUNCO 2L REF } \\
\end{array}$ & 33 & 231 \\
\hline 14 & SANIA 5LJRG & 21 & 147 & 28 & SUNCO 1LREF & 64 & 448 \\
\hline
\end{tabular}

Sumber: Hasil Analisis Data

Dari tabel diatas dapat ditentukan besaran ROP, yakni suatu kondisi level persediaan pada saat perusahaan harus melakukan pemesanan ulang. Reorder Point dalam konteks manajemen persediaan sangat penting karena menjadi salah satu metodo dalam mengambiil keputusan terkait status persediaan dalam mencapai target efektifitas dan efisiensi. Status ROP paling banyak ada pada produk minyak goreng merek Rosebrand 1ltr Ref, sedangkan paling kecil pada produk merek Ikan Dorang SP 1L Btl. d. Menentukan ROP dengan cara menambahkan hasil kali pada langkah c dengan besaran safety stock yang telah ditentukan pada tahap ke 2 .

Penentuan besaran ROP menggunakan rumus:

$\mathrm{ROP}=($ Lead Time $\mathrm{x}$ Kebutuhan perhari $)+$ Safety Stock

Tabel 10. Penentuan Besaran ROP

\begin{tabular}{|c|c|c|c|c|c|c|c|c|c|}
\hline $\mathrm{No}_{0}$ & NamaBarang & \begin{tabular}{|l|}
$\begin{array}{l}\text { Kebutuluan } \\
\text { seluma } \\
\text { leadt time }\end{array}$ \\
\end{tabular} & $\begin{array}{l}\text { Saley } \\
\text { Stock }\end{array}$ & ROP & No. & Nama Barang & $\begin{array}{l}\text { Kebutuhan } \\
\text { selamalead } \\
\text { time }\end{array}$ & $\begin{array}{l}\text { Salely } \\
\text { Stock }\end{array}$ & ROP \\
\hline 1 & BMOLISP SITRRG & 497 & 30 & 527 & 15 & IKANDORANGSPSLBRTL & 84 & 21 & 105 \\
\hline 2 & BMOLLILITRG & 357 & 21 & 378 & 16 & BMOLISP 1LBOT & 567 & 24 & 591 \\
\hline 3 & HEVART5LIRG & 343 & 48 & 391 & 17 & SOVIASLIRG & 140 & 29 & 169 \\
\hline 4 & KUNCIMAS2LREF & 560 & 36 & 596 & 18 & SANA2LREF & 378 & 24 & 402 \\
\hline 5 & BMOLISP LLBTL, & 448 & 47 & 495 & 19 & INGACOLLBOT & 168 & 21 & 189 \\
\hline 0 & SEDAPZLLREF & 574 & 415 & 989 & 20 & ForTUNELl BOT & 651 & 68 & 719 \\
\hline 7 & MADINA5LIRG & 224 & 52 & 276 & 21 & ROSEBRANDSLLRG & 147 & 13 & 160 \\
\hline 8 & ForTuNE2l bor & 504 & 46 & 550 & 22 & SANA ILREF & 637 & 76 & 713 \\
\hline 9 & BMOLLZ1BOT & 427 & 38 & 465 & 23 & ROSE BRAND 2LREF & 308 & 118 & 426 \\
\hline 10 & BMOLSPP ZITREF & 462 & 48 & 510 & 24 & FORTINELLREF & 329 & 40 & 369 \\
\hline 11 & FLLMASLLRG & 161 & 37 & 198 & 25 & IKANDORANGSP LLBTL & 147 & 31 & 178 \\
\hline 12 & ROSE BRAND ILREF & 868 & 190 & 1058 & 26 & SOVIA LREF & 280 & 43 & 323 \\
\hline 13 & BMOLSP HLREF & 721 & 267 & 988 & 27 & SUNCO2LREF & 231 & 47 & 278 \\
\hline 14 & SANIA5LIRG & 147 & 46 & 193 & 28 & SUNCO1LREF & 448 & 45 & 493 \\
\hline
\end{tabular}

Sumber: Hasil Analisis Data

Dari tabel diatas dapat ditentukan besaran ROP, yakni suatu kondisi level persediaan pada saat perusahaan harus melakukan pemesanan ulang. Reorder Point dalam konteks manajemen persediaan sangat penting karena menjadi salah satu metodo dalam mengambiil keputusan terkait status persediaan dalam mencapai target efektifitas dan efisiensi. Status ROP paling banyak ada pada produk minyak goreng merek Rosebrand 1ltr Ref, sedangkan paling kecil pada produk merek Ikan Dorang SP 1L Btl.

\section{Kesimpulan}

Simpulan dari penelitian ini adalah 1). Penerapan metode ABC dalam menentukan kelas persediaan menunjukkan terdapat 28 item minyak goreng yang masuk pada kelas A, sebanyak 21 item masuk pada kelas B, sedangkan sisanya sebanyak 31 item masuk pada kelas C; 2). Penentuan safety stock paling banyak adalah pada item Sedaap 2L Ref sebanyak 251,77 dibulatkan menjadi 252 
buah.; 3). Reoder Point paling banyak adalah pada minyak goreng merek Rosebrand Kemasan Reffil 1 Liter.

\section{Saran}

Bersadarkan kesimpulan tersebut, penulis memberikan saran kepada pengelola Swalayan Mina, bahwa: 1) penentuan kelas untuk setiap item persediaan sangatlah penting, karena pengambil kebijakan dapat mengetahu dengan pasti item barang apa saja yang harus tersedia karena kebutuhan permintaan yang besar dan harga yang mahal. 2) diperkuat dengan penentuan safety stock agar tidak terjadi kehabisan persediaan atau out of stock. 3) metode Reorder Point merupakan pelengkap dalam pengendalian persediaan barang dagangan di Swalayan Mina, dengan mengetahui besaran ROP dalam setiap produk minyak goreng yang memiliki nilai persediaan mencapai $70 \%$, maka Swalayan Mina dapat memesan tepat waktu dan saat pesanan datang, persediaan minyak goreng digudang sudah tepat pada status safety stock.

\section{Daftar Referensi}

Assauri, S. (1999). Manajemen Produksi Dan Operasi (Edisi Revi). Jakarta: Lembaga Penerbitan Fakultas Ekonomi Universitas Indonesia.

Dewi, I. Y. (2010). Analisis pengendalian persediaan bahan baku kertas cd roll with safety stock pada CV. Adinugraha.

Hadi, L. D. dan R. (2004). Manajemen logistik.

Heizer, J., \& Render, B. (2014). Operations Management. Sustainability and Supply Chain Management. In Operations Management. Sustainability and Supply Chain Management (p. 255).

Herjanto, E. (2008). Manajemen Operasi (Edisi Keti). Jakarta: Gramedia.

Ishak, A. (2010). Manajemen Operasi (Edisi Pert). Yogyakarta: Graha Ilmu.

Martani, D., Siregar, S. V., Wardhani, R., Farahmita, A., Tanujaya, E., \& Hidayat, T. (2012). Akuntansi Keuangan Menengah Berbasis PSAK (Jilid 1). Jakarta: PT. Salemba Empat.
Rangkuti, F. (2007). anajemen persediaan : aplikasi dibidang bisnis; pendekatan praktis dengan lebih 40 kasus berikut pembahasannya. Jakarta: PT. Raja Grafindo Persada.

Sugiono, A. (2009). Manajemen Keuangan untuk Praktisi Keuangan. Jakarta: Gramedia Widiasarana Indonesia. 